\title{
Measuring phosphatidic acid phosphohydrolase (EC 3.1.3.4) activity using two phosphomolybdate-based colorimetric methods
}

\author{
Abul H. J. Ullah*, Kandan Sethumadhavan, Jay Shockey \\ Southern Regional Research Center, Agricultural Research Service, USDA, New Orleans, USA \\ Email: ${ }^{*}$ abul.ullah@ars.usda.gov
}

Received 12 October 2012; revised 15 November 2012; accepted 21 November 2012

\begin{abstract}
Phosphatidic acid phosphohydrolase (3-sn-phosphatidate phosphohydrolase, EC 3.1.3.4), also known as PAP, catalyzes the dephosphorylation of phosphatidic acid (PtdOH) to form diacylglycerol (DAG) and inorganic orthophosphate. In eukaryotes, the PAP driven reaction is the committed step in the synthesis of triacylglycerol (TAG). Existing methods for measuring PAP activity rely on the use of radioactive PtdOH. These methods are costly and cumbersome. In this report, we describe a simple assay procedure to measure released inorganic orthophosphate, which is a co-product of the PAP reaction. Each molecule of PtdOH would release one molecule of DAG and one molecule of inorganic orthophosphate $\left(P_{i}\right)$ when subjected to enzymatic breakdown under optimal conditions. Given the published rates of in vitro PAP enzymatic activity from various sources, we proposed that colorimetric determination of released $P_{i}$ is possible. With this view, we performed in vitro PAP activity assays using freshly isolated enzyme from bitter gourd, Momordica charantia, and measured the released $P_{i}$ using two spectrophotometric methods. Both methods gave about 2.0 to 2.25 ๆkat per mg of protein. Thus, it is now possible to perform PAP activity using a simple procedure that uses nonradioactive substrates, provided the sample is dialyzed extensively to lower the intrinsic concentration of free phosphate. The kinetics data presented in this study is comparable to that of other PAP enzymes reported elsewhere, which gives credence to the notion that non-radioactive methods can be used to perform PAP activity.
\end{abstract}

Keywords: Phosphatidic Acid Phosphohydrolase; Fatty Acid Metabolism; Diacyl Glycerol; Inorganic Orthophosphate Measurement

*Corresponding author.

\section{INTRODUCTION}

Oil synthesis in oleaginous plants takes place in developing seed with the aid of a host of lipid biosynthetic enzymes of which phosphatidic acid phosphohydrolase (PAP, 3-sn-phosphatidate phosphohydrolase, EC 3.1.3.4) is of paramount importance. This enzyme cleaves the phosphomonoester bond present in phosphatidic acid ( $\mathrm{PtdOH})$ yielding diacylglycerol (DAG) and $\mathrm{P}_{\mathrm{i}}[1,2]$. The phosphohydrolase reaction catalyzed by this enzyme is represented in Figure 1.

In the Kennedy pathway of TAG synthesis the formation of DAG is the penultimate step. DAG is not only essential for TAG formation, but is also a substrate in the synthesis of the phospholipids phosphatidylethanolamine and phosphatidylcholine $[3,4]$. PAP acts as a pivotal biocatalyst in the metabolic flux between the different classes of glycerolipid within endoplasmic reticulum. PAP has also been shown to play an important role in the phospholipase D signaling pathway $[5,6]$. PAP is present not only in microbes and plants but also in animals; recent studies have shown that human lipin 1 is PAP [7]. Moreover, the lipin 1 deficiency in mouse prevents normal adipose tissue development, which results in lipodystrophy - a disease that results in the loss of body fat and insulin resistance; conversely, lipin 1 promotes obesity and insulin sensitivity $[8,9]$. Lipin 1, a PAP enzyme,

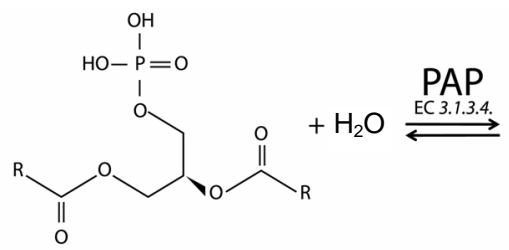

1,2- diacyglycerol 3-phosphate

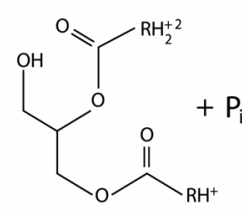

1,2- diacyglycerol
Figure 1. The schematic representation of enzymatic reaction carried out by phosphatidic acid phosphohydrolase (PAP). Phosphatidic acid yields one molecule of DAG and one molecule of inorganic orthophosphate $\left(\mathrm{P}_{\mathrm{i}}\right)$ when the phospho-ester linkage is hydrolyzed by PAP. 
regulates lipid metabolism in mammalian cells; therefore, the biocatalyst could become a target for drug development in combating fat related diseases in humans.

In the biochemical scheme for TAG assembly in developing seeds of oleaginous plants, the formation of DAG from phosphatidic acid by removal of $P_{i}$ is considered a crucial step [10]. If PAP does not function optimally, it could create a bottleneck for TAG synthesis. Therefore, it follows that the knowledge base of general lipid metabolism will benefit from a more thorough understanding of the enzymatic properties of PAP.

Both pharmaceutical and basic plant science research would benefit from a large-scale search for inhibitors and activators of PAP. This search necessitates a sensitive and speedy enzymatic assay. The radioactive assays $[11,12]$ that are currently being used to measure PAP activity are not only expensive but also not conducive to highthroughput screening of potential molecules that control phosphohydrolase activity. Apart from the fact that handling of radionuclide associated with the assay makes the measurements a bit cumbersome, the procedure requires a chloroform-methanol-water phase partition to separate water-soluble ${ }^{32} \mathrm{P}_{\mathrm{i}}$ from chloroform-soluble $\left[{ }^{32} \mathrm{P}\right] \mathrm{PtdOH}$ or thin layer chromatography (TLC) separation of DAG from the substrate, $\mathrm{PtdOH}[11,12]$.

A non-radioactive enzyme assay for a pure $\mathrm{Mg}^{2+}$ dependent PAP was reported in which a malachite green-molybdate reagent was used to measure the released $\mathrm{P}_{\mathrm{i}}$. The reagent produced a colored complex with $P_{i}$ that could be measured using a spectrophotometer at $660 \mathrm{~nm}$ [13]. However, the reported colorimetric method is not suitable for use when cell extracts or crude PAP preparation are being assayed due to a high $P_{i}$ background. The method was reported to be suitable for measureing only purified PAP1 activity where $P_{i}$ background was substantially low.

The colorimetric methods that we are reporting here, however, could be used to measure PAP activity even in crude samples, provided a rapid dialysis step is incorporated to remove inorganic orthophosphate from the protein extracts prior to carrying out the assay. The method was successfully used in our laboratory to measure PAP activity in protein extracts of the developing cotyledons of three cucurbits, namely, Momordica charantia, Luffa cylindrica, and Lagenaria siceraria. However, we report here the results of the experiments performed with Momordica charantia cotyledon extracts.

\section{EXPERIMENTAL PROCEDURES}

\subsection{Source of PAP}

Bitter gourd, Momordica charantia (Indian type variety) was purchased from an oriental grocery in the New Orleans, Louisiana area. The fruits were at a mid-maturity stage, typically about 6 inch in length.

\subsection{Extraction of Soluble PAP from Momordica charantia Developing Cotyledons}

The seeds $(5.0 \mathrm{~g})$ were obtained from the seed cavity of Momordica charantia fruit and washed with $0.9 \%$ ice cold saline solution. The outer coverings of the seeds were removed at room temperature using a scalpel and the cotyledons were removed manually. All subsequent operations were carried out at $4^{\circ} \mathrm{C}$.

A $5.0 \mathrm{~mL}$ aliquot of extraction buffer $(50 \mathrm{mM}$ acetate, $150 \mathrm{mM}$ sodium chloride and $10 \mathrm{mM} \mathrm{MgCl}_{2}, \mathrm{pH} 5.0$ ) was added to the seeds and homogenized using a Tekmar Tissumizer MarkII (Cincinnati, OH) tissue disruptor sequentially at low, medium and high speed for $30 \mathrm{sec}$ at each speed while keeping the sample in an ice bath. The homogenate was allowed to cool on ice for $1 \mathrm{~min}$ between bursts. The sample was then centrifuged at 20,000 $\times \mathrm{g}$ for 30 min using Sorvall RC-5B centrifuge (Miami, FL). The pellet, containing unbroken cotyledons and other tissue debris, was discarded.

The resulting supernatant was dialyzed overnight against imidazole buffer ( $50 \mathrm{mM}$ imidazole, $1 \mathrm{mM} \mathrm{MgCl}_{2}$, pH 6.0) with three buffer changes of $500 \mathrm{~mL}$ each. The resulting supernatant became cloudy after dialysis due to isoelectric precipitation of proteins, which was removed by centrifugation as mentioned above. The supernatant containing $1.69 \mathrm{mg}$ protein per $\mathrm{ml}$, which was estimated by using Coomassie Plus ${ }^{\mathrm{TM}}$ protein assay reagent (Thermo Scientific, Rockford, IL), was used for all subsequent PAP activity measurement and characterization.

\subsection{Measurement of PAP-Catalyzed $P_{i}$ Release}

Two methods were used to measure $\eta$ moles of $\mathrm{P}_{\mathrm{i}}$ released by Momordica charantia PAP from the substrate, dioleoyl-phosphatidate (1,2-dioleoyl-sn-glycero-3-phosphate, sodium salt), which was obtained from Avanti Polar Lipids, Inc. (Alabaster, Alabama). These methods were designated as molybdenum blue or MB method [14, 15] and ammonium molybdate-based acetone-molybdateacid or AMA method $[16,17]$. The enzyme unit, kat, is defined as mole substrate converted per sec.

For the AMA method, the reaction was stopped by the addition of $2 \mathrm{~mL}$ AMA reagent [acetone, $10 \mathrm{mM}$ ammonium molybdate, $5 \mathrm{~N}$ sulfuric acid mixture, 2:1:1 (vol/ $\mathrm{vol} / \mathrm{vol})]$ followed by $100 \mu \mathrm{L}$ of $1 \mathrm{M}$ citrate solution. The resulting turbidity was removed by centrifugation at $12,000 \times \mathrm{g}$ for $6 \mathrm{~min}$ using Eppendorf Model 5415C centrifuge (Westbury, NY) at room temperature. The absorbance of the yellow color developed was read at 355 $\mathrm{nm}$ employing Bio-Rad $\times$ Mark Microplate Spectrophotometer (Hercules, CA).

For the MB method, the enzymatic reaction was typi- 
Table 1. Summary of Momordica charantia PAP activity measurements using two methods.

\begin{tabular}{lll}
\hline Experiments & AMA method & MB method \\
\hline Activity measurements: & $(\eta$ kats/mg of protein \pm SD) & ( $\eta$ kats $/$ mg of protein \pm SD) \\
Using fixed enzyme concentration ${ }^{\mathrm{a}}$ (triplicates) & $2.07 \pm 0.05$ & $2.25 \pm 0.05$ \\
${\text { Determined by } \mathrm{P}_{\mathrm{i}} \text { release over time }}^{\mathrm{b}}$ & $2.04 \pm 0.17$ & $2.37 \pm 0.05$ \\
Measured by increase in enzyme concentrtion $^{\mathrm{c}}$ & $2.18 \pm 0.12$ & $2.15 \pm 0.09$ \\
Post-reaction treatment & None & $20 \min @ 50^{\circ} \mathrm{C}$ \\
$\mathrm{P}_{\mathrm{i}}$ detecting range & upto $500 \eta$ moles & upto $150 \eta \mathrm{moles}$ \\
Enzyme aliquot used & $50 \mu \mathrm{L}$ & 10 to $15 \mu \mathrm{L}$ \\
\hline
\end{tabular}

Note: Spectrophotometric readings between 0.150 and 0.800 were used in the calculations; ${ }^{a}$ Enzymatic reaction for 30 min; ${ }^{b}$ Maximum 25 min by AMA method and 30 min by MB method; ${ }^{c}$ Maximum $40 \mu \mathrm{L}$ by AMA method and $10 \mu \mathrm{L}$ by MB method.

cally incubated at $37^{\circ} \mathrm{C}$ for $30 \mathrm{~min}$ after which it was terminated by the addition of $2 \mathrm{~mL}$ freshly prepared $\mathrm{MB}$ reagent $[1 \mathrm{M}$ sulfuric acid, $2.5 \%$ ammonium heptamolybdate, and $10 \%$ ascorbic acid, (3:1:1, vol $/ \mathrm{vol} / \mathrm{vol})]$. The mixture was incubated at $50^{\circ} \mathrm{C}$ for $20 \mathrm{~min}$ for color development. The resulting turbidity of the final mixture was then removed by centrifugation as described for the AMA method above. The absorbance of the blue color was read at $820 \mathrm{~nm}$ using the microplate spectrophotometer described above. For both methods, control reactions contained all the components of the PAP assay, but the reactions were terminated at zero time. The controls were used to zero the absorbance of the plate reader.

\section{RESULTS}

\subsection{Measurement of PAP Activity}

The phospho-hydrolytic activity of PAP from Momordica charantia that results in the cleavage of $\mathrm{PA}$ into DAG and $P_{i}$ was determined by both AMA and MB methods. A triplicate activity measurements gave $2.25 \eta \mathrm{kat}$ or 135 ๆmoles Pi liberated per min per mg of protein for

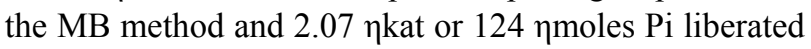
per min per mg of protein for the AMA method at $\mathrm{pH} 6.0$ and $37^{\circ} \mathrm{C}$. Thus, the MB method measured $8.6 \%$ more activity than the AMA method. When incubations were carried out for $30 \mathrm{~min}$, one of the products of PAP-catalyzed reaction, $\mathrm{P}_{\mathrm{i}}$, was generated in sufficient amounts

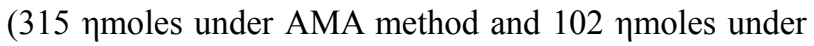
MB method), to allow for spectrophotometric quantitation. Table 1 summarizes the results as determined by both methods. The detection range of the AMA method was about three times higher than the MB method; therefore, less enzymes were used in the MB method. The AMA method offered the advantage of being simpler than the MB method, because no post-reaction treatment was needed to develop the color.

\section{2. $P_{i}$ Measurement versus PAP Concentration}

To show that release of $\mathrm{P}_{\mathrm{i}}$ from $\mathrm{PtdOH}$ increases as a function of PAP concentration, experiments were performed with variable amounts of soluble protein from Momordica charantia cotyledons. The results are shown in Figure 2 for the AMA method and Figure 3 for the MB method. About $37 \eta$ moles of $P_{i}$ was released in 30 min at $\mathrm{pH} 6.0^{\circ} \mathrm{C}$ and $37^{\circ} \mathrm{C}$ when PAP assay was conducted with $5 \mu \mathrm{L}$ of crude extract. This value increased to $244 \eta$ moles when $40 \mu \mathrm{L}$ of crude extract was assayed for identical lengths of time at the same $\mathrm{pH}$ and temperature (Figure 2).

Likewise, in the MB method, 26 mmoles of $\mathrm{P}_{\mathrm{i}}$ was released from the substrate in 30 minutes at $\mathrm{pH} 6.0$ and $37^{\circ} \mathrm{C}$ when the assay was conducted with $4 \mu \mathrm{L}$ of crude extract. This value increased to $67.9 \eta$ moles when $10 \mu \mathrm{L}$ of crude extract was assayed for identical time at the same $\mathrm{pH}$ and temperature (Figure 3). When the assay was conducted for $30 \mathrm{~min}$ with $10 \mu \mathrm{L}$ of crude extract at $37^{\circ} \mathrm{C}$, both the method gave a similar value, which is 68 ๆmoles of $P_{i}$ released from the substrate. Data analysis revealed that approximately three times more PAP activity can be assayed using the AMA method compared to the MB method (Figures 2 and $\mathbf{3}$ ). This is due solely to the sensitivity of the two reagents for binding $P_{\mathrm{i}}$. In the case of the AMA method, 1 O.D. at $355 \mathrm{~nm}$ represents

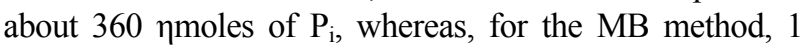
O.D. at $820 \mathrm{~nm}$ represents approximately 120 ๆmoles of $\mathrm{P}_{\mathrm{i}}$.

\subsection{Measurement of $P_{i}$ Released by $P A P$ as a Function of Time}

To investigate the rate linearity of PAP activity as a function of time, the released $\mathrm{P}_{\mathrm{i}}$ was measured by both AMA and MB methods. The results are shown in Figures 4 and 5. Because of the higher sensitivity of $P_{i}$ detection using the AMA method, $50 \mu \mathrm{L}$ of enzyme was used, 


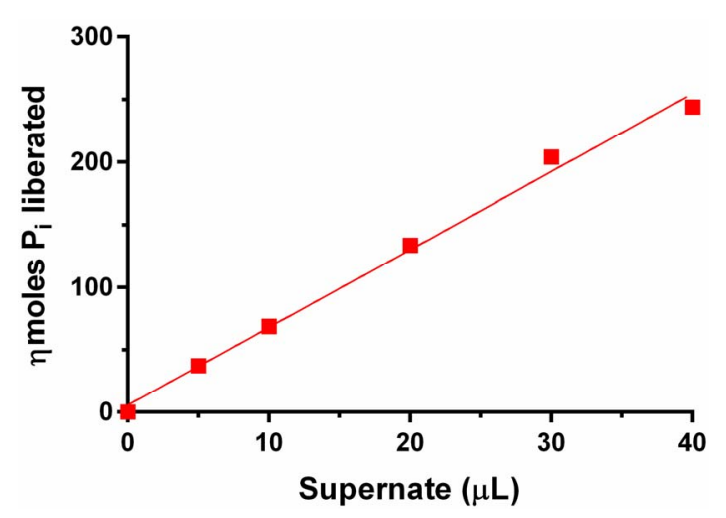

Figure 2. $\mathrm{PAP}$ catalyzed liberation of $\mathrm{P}_{\mathrm{i}}$ as a function of increasing amounts of supernatant derived from developing cotyledons of Momordica charantia. Liberated $\mathrm{P}_{\mathrm{i}}$ was measured by AMA method. The standard deviation was \pm 5.4 per cent of the average of nkat per mg of protein $(n=6)$.

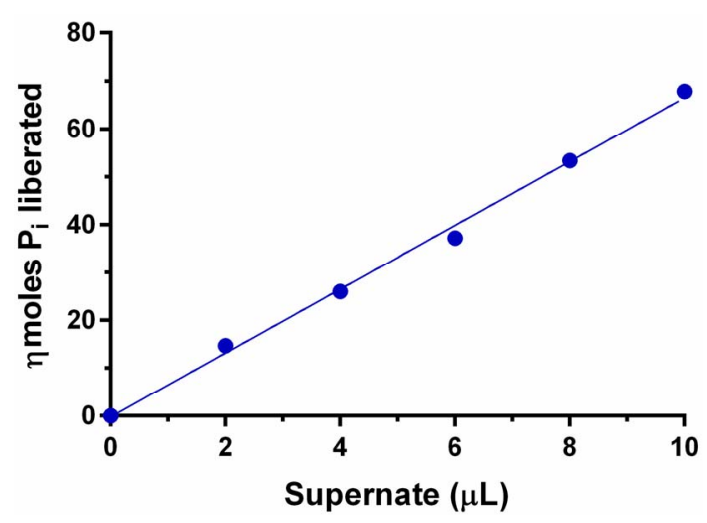

Figure 3. PAP catalyzed liberation of $P_{i}$ as a function of increasing amounts of supernatant derived from developing cotyledons of Momordica charantia. The liberated $\mathrm{P}_{\mathrm{i}}$ was measured by $\mathrm{MB}$ method. The standard deviation was \pm 3.8 per cent of the average of nkat per $\mathrm{mg}(\mathrm{n}=5)$.

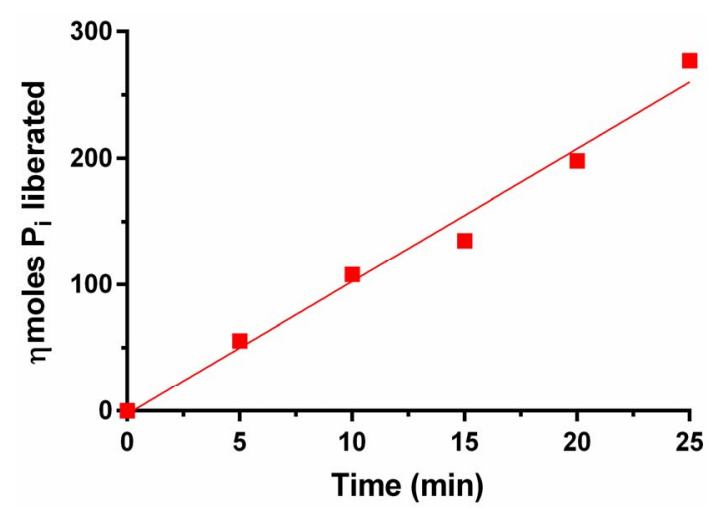

Figure 4. PAP catalyzed liberation of $P_{i}$ as a function of incubation time. The liberated $P_{i}$ was measured by AMA method. The standard deviation was \pm 8.1 per cent of the average of nkat per mg $(n=6)$.

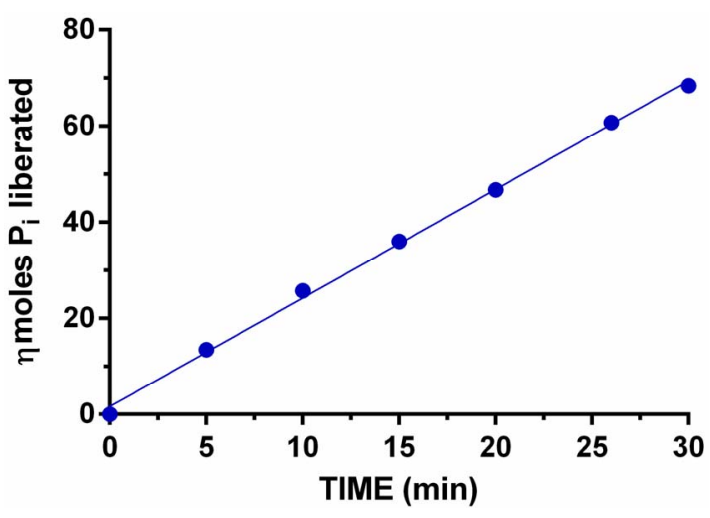

Figure 5. $\mathrm{PAP}$ catalyzed liberation of $\mathrm{P}_{\mathrm{i}}$ as a function of incubation time. The liberated $\mathrm{P}_{\mathrm{i}}$ was measured by MB method. The standard deviation was \pm 1.9 percent of the average of nkat per mg $(n=6)$.

whereas, $10 \mu \mathrm{L}$ sample was used to perform the time course study with the MB method. The enzyme released $P_{i}$ linearly throughout the 30 min course as determined by both methods; however, the MB method gave a nearly straight line (Figure 5). Under the AMA method, a higher level of $\mathrm{P}_{\mathrm{i}}$ could be detected as compared to the MB method, which indicates that the AMA method is more sensitive than the MB method.

\section{DISCUSSION}

In this communication we reported two colorimetric methods to measure PAP activity. The enzyme liberated DAG and inorganic orthophosphate $\left(\mathrm{P}_{\mathrm{i}}\right)$ when the phosphomonoester bond present in phosphatidic acid was hydrolyzed. The liberated $\mathrm{P}_{\mathrm{i}}$ reacted with molybdate under acidic conditions to absorb at $355 \mathrm{~nm}$ in presence of acetone and at $820 \mathrm{~nm}$ in presence of ascorbic acid. Table 1 summarizes the activity measurements performed by Momordica charantia phosphatidic acid phosphohydrolase as determined by both AMA and MB methods. Additional data were included in the table to reflect the detection range of each method, the heating requirement for color generation in the MB method, and the amounts of sample needed to perform the PAP assay for each method.

While both methods could measure released $\mathrm{P}_{\mathrm{i}}$ resulting from phosphohydrolase activity, the AMA method was able to measure up to 500 nmoles of $\mathrm{P}_{\mathrm{i}}$, compared to 150 ๆmoles for the MB method (Table 1). In this respect the AMA method was deemed to be superior to the MB method. Furthermore, the MB method requires an additional $20 \mathrm{~min}, 50^{\circ} \mathrm{C}$ incubation step after the addition of color-developing reagent (sulfuric acid-ammonium hepta molybdate-ascorbic acid); this step is not necessary when using the AMA method.

A HPLC-fluorescence detection method for the deter- 
mination of phosphatidic acid phosphohydrolase activity was reported in which the unreacted substrate was separated from the product by HPLC and the latter was detected by fluorimetry [18]. The method is not as simple or cost-effective as the one we are reporting in this communication.

The colorimetric method we described here was found to be as sensitive as other colorimetric $[19,20]$ and radioactive methods [21] in determining low $\eta$ mole quantities of either $\mathrm{P}_{\mathrm{i}}$ or DAG generated by PAP.

In summary, we described here two colorimetric methods to measure $\mathrm{P}_{\mathrm{i}}$ released by PAP from 1,2-dioleoyl-sn-glycero-3-phosphate, a commonly used representtative form of $\mathrm{PtdOH}$. The level of activity as determined by these methods compare favorably with radioactive PAP activity assay methods [21,22]. Therefore, non-radioactive phosphatidic acid could be used as the substrate in place of its radioactive counterpart to measure this important catalytic reaction. The method reported here is also substantially faster, as the cumbersome TLC separation and scintillation counting steps common to the radioactive methods are avoided. The use of non-radioactive $\mathrm{PtdOH}$ will allow for analysis of a wider range of potential PtdOH substrates compared to the limited number of commercially available radiolabeled $\mathrm{PtdOH}$ species. Furthermore, the colorimetric procedure we detailed here is also a substantially more cost-effective than the radioactive methods.

\section{CONCLUSION}

In this article, we described two simple spectrophotometric methods to measure inorganic orthophosphate, which is a co-product of phosphatidic acid phosphohydrolase (PAP) reaction. Each molecule of $\mathrm{PtdOH}$, the substrate, would release one molecule of diacylglycerol (DAG) and one molecule of inorganic orthophosphate $\left(\mathrm{P}_{\mathrm{i}}\right)$ when subjected to enzymatic breakdown under optimal conditions. Given the published rates of in vitro PAP enzymatic activity from various sources, we proposed that colorimetric determination of released $\mathrm{P}_{\mathrm{i}}$ is possible. With this view, we performed in vitro PAP activity assays using freshly isolated enzyme from bitter gourd, Momordica charantia, and measured the released $\mathrm{P}_{\mathrm{i}}$ using two spectrophotometric methods. Both methods gave about 2.0 to 2.25 nkat per $\mathrm{mg}$ of protein. Thus, it is now possible to perform PAP activity assays using a simple procedure that uses nonradioactive substrates, provided the sample is dialyzed extensively to lower the intrinsic concentration of free phosphate. The kinetics data presented in this study is comparable to that of other PAP enzymes reported elsewhere, which gives credence to the notion that non-radioactive methods can also be used to perform PAP activity, facilely.

\section{REFERENCES}

[1] Smith, S.W., Weiss, S.B. and Kennedy, E.P. (1957) The enzymatic dephosphorylation of phosphatidic acids. Journal of Biological Chemistry, 228, 915-922.

[2] Carman, J.M. (1997) Phosphatidate phosphatases and diacylglycerol pyrophosphate phosphatases in Saccharomyces cerevisiae and Escherichia coli. Biochimica et Biophysica Acta, 1348, 45-55. doi:10.1016/S0005-2760(97)00095-7

[3] Kocsi, M.G. and Weselake, R.J. (1996) Phosphatidate phosphatases of mammals, yeast, and higher plants. Lipids, 31, 785-802. doi:10.1007/BF02522974

[4] Nanjundan, M. and Possmayer, F. (2003) Pulmonary phosphatidic acid phosphatase and lipid phosphate phosphohydrolase. American Journal of Physiology Lung Cell Molecular Physiology, 284, L1-L23.

[5] Exton, J.H. (1990) Signaling through phosphatidylcholine breakdown. Journal of Biological Chemistry, 265, 1-4.

[6] Billah, M.M. and Anthes, J.C. (1990) The regulation and cellular functions of phosphatidylcholine hydrolysis. Biochemical Journal, 269, 281-291.

[7] Hans, G.S., Wu, W.I. and Carman, G.M. (2006) The Saccharomyces cerevisiae lipin homolog is a $\mathrm{Mg}^{2+}$-dependent phosphatidate phosphatase enzyme. Journal of Biological Chemistry, 281, 9210-9218.

[8] Peterfy, M., Phan, J., Xu, P. and Reue, K. (2001) Lipodystrophy in the fld mouse results from mutation of a new gene encoding a nuclear protein, lipin. Nature Genetics, 27, 121-124. doi:10.1038/83685

[9] Phan, J. and Reue, K. (2005) Lipin, a lypodystrophy and obesity gene. Cell Metabolism, 1, 73-83. doi:10.1016/j.cmet.2004.12.002

[10] Carman, G. and Han, G.S. (2009) Phosphatidic acid phosphatase, a key enzyme in the regulation of lipid synthesis. Journal of Biological Chemistry, 284, 2593-2597. doi:10.1074/jbc.R800059200

[11] Carman, G.M. and Lin, Y.P. (1991) Phosphatidate phosphatase from yeast. Methods in Enzymology, 197, 548553. doi:10.1016/0076-6879(91)97182-X

[12] Martin, A., Gomez-Munoz, A., Jamal, Z. and Brindley, D.N. (1991) Characterization and assay of phosphatidate phosphatase. Methods in Enzymology, 197, 553-563. doi:10.1016/0076-6879(91)97183-Y

[13] Habriluk, T., Lozy, F., Siniossoglou, S. and Carman, G.M. (2008) Colorimetric determination of pure $\mathrm{Mg}^{2+}$-dependent phosphatidate phosphatase activity. Analytical Biochemistry, 373, 392-394. doi:10.1016/j.ab.2007.08.037

[14] Chen, P.S., Toribara, J.T.Y. and Warner, H. (1956) Microdetermination of phosphorus. Analytical Chemistry, 28, 1756-1758. doi:10.1021/ac60119a033

[15] Weaver, J.D., Ullah, A.H.J., Sethumadhavan, K., Mullaney, E. J. and Lei, X.G. (2009) Impact of assay conditions on activity estimate and kinetics: Comparison of 
Aspergillus niger PhyA and Escherichia coli AppA2 phytases. Journal of Agricultural and Food Chemistry, 57, 5315-5320. doi:10.1021/jf900261n

[16] Heinonen, J.K. and Lahti, R. J. (1981) A new and convenient colorimetric determination of inorganic orthophosphate and its application to the assay of inorganic pyrophosphatase. Analytical Biochemistry, 113, 313-317. doi:10.1016/0003-2697(81)90082-8

[17] Ullah, A.H.J., Sethumadhavan, K. and Mullaney, E.J. (2005) Monitoring of unfolding and refolding in fungal phytase (PhyA) by dynamic light scattering. Biochemical Biophysical Research Communications, 327, 993-998. doi:10.1016/j.bbrc.2004.12.111

[18] Burgdorf, C., Prey, A., Richardt, G. and Kurz, T. (2008) A HPLC-fluorescence detection method for determination of phosphatidic acid phosphohydrolase activity: Application in human myocardium. Analytical Biochemistry, 374, 291-297. doi:10.1016/j.ab.2007.10.039

[19] Moore, T.S., Lord, J.M., Kagawa, T. and Beevers, H.
(1973) Enzymes of phospholipid metabolism in the endoplasmic reticulum of castor bean endosperm. Plant Physiology, 52, 50-53. doi:10.1104/pp.52.1.50

[20] Ichihara, K., Norikura, S. and Fujii, S. (1989) Microsomal phosphatidate phosphatase in maturing safflower seeds. Plant Physiology, 90, 413-419.

doi:10.1104/pp.90.2.413

[21] Pearce, M.L. and Slabas, A.R. (1989) Phosphatidate phosphatase from avocado (Persea Americana)-Purification, substrate specificity and possible metabolic implications for the Kennedy pathway and cell signaling in plants. Plant Journal, 14, 555-564. doi:10.1046/j.1365-313X.1998.00152.x

[22] Eastmond, P.J., Quettier, A.-L., Kroon, J.T.M., Craddock, C., Adams, N. and Slabas, A.R. (2010) Phosphatidic acid phosphohydrolase 1 and 2 regulate phospholipid synthesis at the endoplasmic reticulum in Arabidopsis. Plant Cell, 22, 2796-2811. 